\title{
Long-Term Efficacy and Safety of Intravenous Injection of Clonal Mesenchymal Stem Cells Derived From Bone Marrow in Five Adults With Moderate to Severe Atopic Dermatitis
}

\section{Hyun-Tae Shin}

Inha University Hospital https://orcid.org/0000-0003-1799-5860

Si Hyub Lee

Inha University Hospital

Hee Seong Yoon

Inha University Hospital

Ji Hye Heo

Inha University Hospital

\section{Seon Bok Lee}

Inha University Hospital

Ji Won Byun

Inha University Hospital

Jeonghyun Shin

Inha University Hospital

\section{Yun-Kyoung Cho}

SCM Ligescience

\section{Eunkyung Chung}

SCM Lifesciences

\section{Myung-Shin Jeon}

Inha University Hospital

\section{Sun U. Song}

Inha University Hospital

Gwang Seong Choi ( $\nabla$ garden@inha.ac.kr)

Inha University School of Medicine https://orcid.org/0000-0002-5766-0179

Short report

Keywords: Atopic dermatitis, Mesenchymal stem cell, Long-term efficacy and safety

Posted Date: September 22nd, 2020 
DOI: https://doi.org/10.21203/rs.3.rs-71604/v1

License: (c) (1) This work is licensed under a Creative Commons Attribution 4.0 International License. Read Full License

Version of Record: A version of this preprint was published at The Journal of Dermatology on May 14th, 2021. See the published version at https://doi.org/10.1111/1346-8138.15928. 
2 Title: Long-term efficacy and safety of intravenous injection of clonal mesenchymal stem cells

3 derived from bone marrow in five adults with moderate to severe atopic dermatitis

4 Authors: Hyun-Tae Shin ${ }^{1 *}$, Si Hyub Lee ${ }^{1 *}$, Hee Seong Yoon ${ }^{1}$, Ji Hye Heo ${ }^{1}$, Seon Bok Lee ${ }^{1}, \mathrm{Ji}$

5 Won Byun ${ }^{1}$, Jeonghyun Shin ${ }^{1}$, Yun-Kyoung $\mathrm{Cho}^{2}$, Eunkyung Chung ${ }^{2}$, Myung-Shin Jeon ${ }^{3}$, Sun U.

6 Song ${ }^{2,3 \S}$, and Gwang Seong Choi ${ }^{1 \S}$.

$7 \quad{ }^{1}$ Department of Dermatology, Inha University School of Medicine, Incheon, Republic of Korea.

$8 \quad{ }^{2}$ SCM Lifesciences Co. Ltd., Incheon, Republic of Korea.

$9{ }^{3}$ Department of Integrated Biomedical Sciences, Inha University School of Medicine, Incheon,

10 Republic of Korea.

11

$12{ }^{\S}$ Co-corresponding authors

13 Sun U. Song

14 Department of Integrated Biomedical Sciences, Inha University School of Medicine, Inhang-ro

15 27, Jung-gu, Incheon, 22332, Republic of Korea

16 E-mail: sunuksong@inha.ac.kr

17 Tel: +82-32-890-2460, Fax: Fax: +82-32-891-2277

18 Gwang Seong Choi

19 Department of Dermatology, Inha University School of Medicine, Inhang-ro 27, Jung-gu,

20 Incheon, 22332, Republic of Korea

21 E-mail: garden@inha.ac.kr

22 Tel: $+82-32-890-2238$, Fax: $+82-32-890-2236$ 
$24{ }^{*}$ These authors contributed equally to this work.

25 


\section{ABSTRACT}

27 Atopic dermatitis is a chronic and relapsing inflammatory skin disease that is treated with

28 immunosuppressants. However, long-term use of immunosuppressants may cause toxicity and

29 severe side effects. To confirm the long-term efficacy and safety of clonal mesenchymal stem

30 cell therapy, we performed investigator-initiated clinical trials and long-term observation in five

31 adult patients with moderate to severe atopic dermatitis that was refractory to conventional

32 treatments. The clinical response assessment values such as eczema area and severity index

33 (EASI) improved significantly at 16 weeks, and 80\% (4/5) of the patients achieved EASI-50

34 after one or two treatment cycles. Patients were observed for long-term efficacy and safety for an

35 average of 38 weeks (range: 16-86 weeks) and showed no serious side effects. Among the

36 cytokines tested, CCL-17, IL-13 and IL-22 significantly decreased at the endpoint of the five

37 participants, two patients who maintained good clinical response over 84 weeks showed

38 increased IL-17 cytokine levels in the blood.

\section{KEY WORDS}

41 Atopic dermatitis, Mesenchymal stem cell, Long-term efficacy and safety 


\section{INTRODUCTION}

45 Atopic dermatitis (AD) is a chronic, relapsing inflammatory skin disease accompanied by severe

46 itching and shows heterogeneous phenotypes. In addition to cutaneous symptoms, many studies

47 have reported that moderate to severe AD significantly affects a patient's emotional and

48 psychological well-being.[1,2] $\mathrm{AD}$ is a major public health burden worldwide, with a lifetime

49 prevalence of $10-20 \%$ in children and $3-7 \%$ in adults.[3-6]

50 The treatment of $\mathrm{AD}$ varies according to the severity of the disease, with severe cases needing

51 systemic immunosuppressants.[7] However, long-term use of immunosuppressants may cause

52 severe toxicity and side effects. Biologics that target a specific cytokine show long-term safety

53 and efficacy in patients with moderate to severe $\mathrm{AD}[8]$; however, the proportion of patients who

54 have not achieved complete or nearly complete disease elimination is still high.[2, 9] Moreover,

55 those drugs should be treated through multiple administrations to achieve sufficient efficacy.

56 Mesenchymal stem cells (MSCs) are undifferentiated, and multipotent cells have

57 immunomodulatory and immune inhibitory properties.[10, 11] Therefore, MSCs have been used

58 as therapeutic agents in autoimmune and chronic inflammatory diseases such as graft versus host

59 disease, Crohn's disease, refractory systemic lupus erythematosus, and systemic sclerosis.[12] A

60 few studies have reported the effect of MSC therapy on inflammatory skin conditions in

61 experimental animal models and clinical samples.[13, 14] However, reports on long-term

62 efficacy and safety of MSC therapy for AD are still limited.

63 We performed an investigator-initiated clinical trial to demonstrate the efficacy and safety of

64 multiple doses of allogeneic bone marrow-derived clonal MSCs in five adult patients with

65 moderate to severe $\mathrm{AD}$ that was refractory to the conventional treatments. Furthermore, we 
66 conducted long-term observation of the patients to confirm the long-term efficacy and safety of

67 clonal MSC therapy and analyzed cytokine biomarkers in the blood of the participants.

\section{MATERIALS AND METHODS}

\section{Investigator-initiated clinical trial design}

72 A single-center, open-labeled investigator-initiated clinical trial for the therapeutic use of

73 allogeneic bone marrow-derived clonal MSCs (SCM Lifesciences Co. Ltd., Incheon, Republic of

74 Korea) in adults with moderate to severe AD was conducted with prior approval from the Korean

75 Ministry of Food and Drug Safety. The trial was conducted over a period of 16 weeks (treatment

76 for 4 weeks and follow-up for 12 weeks) and was followed by an observation period. In this

77 clinical trial, $1.0 \times 10^{6}$ cells $/ \mathrm{kg}$ dose of SCM-CGH (fresh stem cell product) or SCM-AGH (frozen

78 stem cell product) (SCM Lifesciences Co. Ltd., Incheon, Republic of Korea) was administered

79 intravenously 3 times every 2 weeks at $2-4.5 \mathrm{~mL} / \mathrm{min}$ infusion rate to enrolled patients. One

80 patient (S004) was injected with the frozen form of clonal MSCs for two cycles while the other

81 patients were injected with the fresh form. The multipotency including the capacity to

82 differentiate into the three major mesenchymal lineages (osteoblasts, adipocytes, and

83 chondrocytes) and the expression pattern of specific cell surface markers of general MSCs were

84 confirmed in all clonal MSC lines utilized in this trial. Other detailed of the study design are in

85 Supplemental Study Protocol.

86 After 16 weeks of the trial, we followed up to confirm the period during which the patient's

87 improved symptoms are maintained by oral antihistamines and/or topical medications without

88 additional use of systemic steroids and systemic immunomodulators. Long-term safety and 
89 effectiveness were evaluated every two months. If the symptoms worsened during follow-up in

90 patients who had improved clinical symptoms during the trial cycle, an additional cycle of

91 treatments was conducted. Evaluation and follow-up of the additional cycle of treatments was

92 conducted in the same way as the first trial.

\section{Participants}

95 This clinical trial included healthy adults with moderate to severe AD diagnosed according to

96 the criteria of Hanifin and Rajka.[15] The inclusion criteria included moderate to severe AD

97 (scoring atopic dermatitis [SCORAD] $>20$ ), age from 20 to 60 years, and persistent symptoms

98 ( $\geq 6$ months). The exclusion criteria are in Supplemental Study Protocol.

\section{Measurement of cytokine biomarkers}

101 During the treatment cycle and follow-up period, blood was collected, allowed to clot at room

102 temperature for $30 \mathrm{~min}$, and then centrifuged for $10 \mathrm{~min}$ at $400 \times \mathrm{g}$. Serum samples were

103 aliquoted, frozen at $-80^{\circ} \mathrm{C}$, and thawed immediately prior to analysis. Quantification of CCL-17

104 (TARC), CCL-22 (MDC), IL-13, IL-17, IL-18, IL-22 (R\&D Systems, Inc., Minneapolis, MN,

105 USA), and IgE (Thermo Fisher Scientific Inc., Waltham, MA, USA) was performed by enzyme-

106 linked immunosorbent assay (ELISA) with the appropriate dilution factor (Supplementary

107 Table 1). All measurements were performed in duplicate. The ELISA kits were used according

108 to the manufacturer's instruction. Optical densities were measured at $450 \mathrm{~nm}$ with wavelength

109 correction at $540 \mathrm{~nm}$ using a Gen5 Microplate Reader (BioTek Instruments Inc., Winooski, VT, 110 USA). 


\section{Statistical analyses}

113 Statistical analyses were performed using R software version 3.6.0 (R Foundation, Vienna,

114 Austria). Wilcoxon signed-rank test was performed to evaluate the statistical significance of the

115 change in clinical and experimental assessment values between the scores documented at the

116 baseline visit and the endpoint. For statistical tests, the level of significance was set at $p<0.05$.

118 RESULTS

\section{Characteristics of patients}

120 This clinical trial included five patients who did not respond to conventional treatments

121 (Supplementary Table 2). The mean age of the patients was 23 years (range: 20-29 years). The 122 trial included $60 \%(3 / 5)$ men and 40\% (2/5) women. No patient reported any other current

123 medical condition in addition to AD. The mean EASI was 31.5 (range: 15.5-40.0) at the baseline,

124 and mean SCORAD was 66.2 (range: 51.0-76.1). All patients completed one cycle of the clinical 125 trial, and except S001, four patients were subjected to a second cycle due to exacerbation of AD.

\section{Improvement of AD using clonal MSCs}

128 All primary efficacy endpoints including a mean reduction of EASI, SCORAD, BSA (body

129 surface area), and IGA (investigator global assessment) in both cycles were statistically

130 significant (Figure 1A and Supplementary Table 3). Both cycles were treated using the same

131 protocol, and only S005 in the second cycle received two additional injections of MSCs due to

132 exacerbation of $\mathrm{AD}$ symptoms during the injection period. EASI reduction at the endpoint for

133 each patient were as follows, S001: $87 \%$ in the 1 st cycle; S002: $82 \%$ in the 1 st cycle and $56 \%$ in 
134 the 2nd cycle; S003: $33 \%$ in the 1st cycle and 50\% in the 2nd cycle; S004: 5\% in the 1st cycle

135 and 51\% in the 2nd cycle; and S005: 46\% in the 1 st cycle and 37\% in the 2nd cycle. S001

136 achieved more than 50\% reduction in EASI (EASI-50 response) in the first cycle, and S002

137 achieved EASI-50 response in both cycles. S003 and S004 did not achieve EASI-50 response in

138 the first cycle, but achieved it in the second cycle. S005 did not achieve EASI-50 response in

139 both cycles. For secondary efficacy endpoints, a reduction in eosinophil count and ECP was

140 observed, but it was not statistically significant, and total $\operatorname{IgE}$ in the undiluted serum was similar

141 at the end of both cycles (Supplementary Figure 1 and Supplementary Table 3). Most

142 primary and secondary endpoints were evaluated at 12 weeks after clonal MSC therapy, and only

143 those of the additional cycle for S003 were evaluated at 17 weeks.

145 Long-term efficacy and safety of MSC therapy

146 Participants were followed up for an average of 38 weeks (range: 16-86 weeks) after screening

147 to check how long the improved symptoms were maintained without additional use of systemic

148 steroids and systemic immunomodulators (Figure 1B). S001, who underwent only the first cycle

149 treatment, maintained the EASI-50 response for 84 weeks (Figure 1B and Figure 2A).

150 Interestingly, S002, who improved with the first cycle treatment and worsened during follow-up,

151 maintained the EASI-50 response for 86 weeks after screening of the second cycle (Figure 1B

152 and Figure 2B). S001 and S005 were lost to follow-up observation after the last visit, and S002

153 continued to present an improved status. During the observation period, S003 and S004

154 presented exacerbated symptoms, and the observation was discontinued due to the use of

155 systemic steroids or systemic immunomodulators. 
156 There were no serious adverse events associated with MSC therapy in long-term observation.

157 S001 had acute upper respiratory tract infection (URI) and otitis externa during the trial cycle

158 and recovered completely within two weeks. S002 also had acute URI and recovered completely

159 within two weeks. S003 had cellulitis on the right ankle 4 weeks after MSC injection, which

160 improved after oral antibiotic treatment for 29 days. S005 had intermittent non-specific chest

161 pain lasting about 10 min during the injection period, which improved without special treatment.

162 Local inflammatory reaction, skin rash, urticaria, etc., did not occur at the injection site during

163 the administration of MSCs. Severe allergic reactions such as shortness of breath, wheezing,

164 sudden changes in blood pressure, palpitations, and side effects due to vascular blockage after

165 intravenous administration did not occur.

166

167 Cytokine biomarkers in response to treatment

168 We measured several biomarkers (CCL-17, CCL-22, IL-13, IL-18, IL-22, and IgE) using ELISA

169 with the appropriate dilution factor (Supplementary Table 1). CCL-17, IL-13, and IL-22

170 significantly decreased at the endpoint, and other biomarkers showed decreasing trends during

171 the experiments (Supplementary figure 2 and Supplementary Table 4). Interestingly, S001

172 and S002 achieved EASI-50 response in the first cycle treatment and maintained long-term

173 efficacy from screening (S001: for 84 weeks after the first cycle treatment, S002: for 86 weeks

174 after the second cycle treatment) and showed relatively high levels of IL-17 in their blood than

175 the other patients.

176

177 DISCUSSION 
178 To demonstrate the efficacy and safety of multiple doses of allogeneic clonal MSCs derived

179 from bone marrow, we performed an investugator-initiated clinical trial in five adult patients

180 with moderate to severe $\mathrm{AD}$ refractory to the conventional treatments and observed the patients

181 to confirm the long-term efficacy and safety of clonal MSC therapy. The EASI, SCORAD, BSA,

182 and IGA of the patients improved significantly after about 16 weeks and $80 \%(4 / 5)$ of the

183 patients achieved EASI-50 after one or two cycles of treatment. Patients were observed for

184 efficacy and safety for an average of 38 weeks (range: 16-86 weeks) and showed no serious side

185 effects. Among the participants, two patients were shown to maintain long-term (S001: 84 weeks

186 and S002: 86 weeks) efficacy without systemic steroids and immunomodulators, and increased

187 levels of IL-17 cytokine in blood circulation.

188 AD appears to be a relatively heterogeneous disease that is driven by both Th2 and Th22, with 189 variable Th1 and Th17 activation.[16, 17] Novel IL-4R (Th2)-targeting agents such as

190 dupilumab for AD showed significant improvement, but the proportion of patients who have not 191 achieved complete or nearly complete disease elimination is still high. [2, 9, 16] Studies with

192 Asian AD, early-onset pediatric AD, and intrinsic AD reported higher IL-17 expression in their 193 cohort.[18-20] In this clinical trial, two patients (S001 and S002) responded well to MSC therapy 194 and had relatively high IL-17 (Th17) cytokine levels (Figure 3). Some cancer studies have 195 described a connection between the Th17 cell-related cytokines and cancer stem cells (CSCs) 196 and reported that IL-17 could contribute to CSCs maintenance and stimulate their self-

197 renewal.[21, 22] In this regard, MSC therapy has the potential to be a good therapeutic option for 198 moderate to severe AD with high IL-17 levels.

199 The limitation of this study is that a small number of patients with AD were enrolled in the 200 clinical trial. Therefore, large-scale clinical trials are necessary to confirm the long-term efficacy 
201 and safety for moderate to severe AD. Moreover, we did not control the type of clonal MSC lines

202 for AD treatment (Supplementary table 2). Although all clonal cell lines had similar properties

203 to general MSCs, the variation in response due to changes in cell lines could not be ruled out.

204 Through this clinical trial, we provide some evidence for the long-term efficacy and safety of

205 clonal MSC therapy in moderate to severe AD patients without serious adverse events and

206 suggest that high IL-17 levels may be associated with good clinical improvement with MSC

207 therapy.

208 


\section{LEGENDS}

210 Figure 1. Clinical response of patients with atopic dermatitis to clonal mesenchymal stem cell

211 therapy. (A) Comparison of clinical response between screening and endpoint (followed up at

212 about 16 weeks). The significance of the results was evaluated with Wilcoxon signed-rank test.

213 EASI: Eczema Area and Severity Index, SCORAD: SCORing Atopic Dermatitis, BSA: Body

214 Surface Area, IGA: Investigator Global Assessment. (B) Changes in Eczema Area and Severity

215 Index (EASI) score of atopic dermatitis patients treated with clonal mesenchymal stem cells. ${ }^{* *} p$

$216<0.01,{ }^{*} p<0.05$

217 Figure 2. Photographs of atopic dermatitis patients with good long-term response to clonal 218 mesenchymal stem cell therapy. (A) S001 patient. (B) S002 patient. f/u: follow-up.

220 Supplementary figure 1. Comparison of laboratory response of atopic dermatitis to clonal

221 mesenchymal stem cell therapy between screening and endpoint (followed up at about 16 weeks).

222 The significance of the results was evaluated with Wilcoxon signed-rank test. ECP: Eosinophil

223 Cationic Protein

224 Supplementary figure 2. Comparison of biomarkers of atopic dermatitis in response to clonal 225 mesenchymal stem cell therapy between screening and endpoint (followed up at about 16 weeks).

226 The significance of the results was evaluated with Wilcoxon signed-rank test. * $p<0.05$ 


\section{LIST OF ABBREVIATIONS}

234 EASI: eczema area and severity index

235 AD: atopic dermatitis

236 MSCs: mesenchymal stem cells

237 SCORAD: scoring atopic dermatitis

238 ELISA: enzyme-linked immunosorbent assay

239 URI: upper respiratory tract infection

240 CSCs: cancer stem cells

241 BSA: body surface area

242 IGA: investigator global assessment

\section{DECLARATIONS}

\section{Ethics approval and consent to participate}

246 This investugator-initiated clinical trial for each participant was reviewed and approved by the

247 institutional review board of Inha University Hospital [IRB No. 2017-06-009, 2017-12-015, 248 2017-09-019, 2018-04-031, 2018-05-005, 2018-12-005, 2018-12-032], and was performed in 249 accordance with the principles of the Declaration of Helsinki, Korean Good Clinical Practice 
250 guidelines, and local regulatory requirements. All patients provided informed consent prior to 251 participation.

252

\section{Consent for publication}

254 Consent for publication was obtained from participants of the clinical trial.

256 Availability of data and materials

257 All data analysed during this study are included in this published article and its supplementary 258 information files.

259

\section{Competing interests}

261 The authors declare that they have no known competing financial interests or personal

262 relationships that could have appeared to influence the work reported in this paper.

264 Funding

265 This work was supported by INHA UNIVERSITY HOSPITAL Research Grant.

\section{Authors' contributions}

268 H.-T.S. and S.H.L. performed all analysis of data and writing the manuscript with guidance from

269 G.S.C.. S.H.L. performed enrollment of participants and the treatment of trial drugs. S.H.L., 
H.S.Y., J.H.H., S.B.L., J.W.B., J.S., and G.S.C. contributed to clinical data collection. Y.-K.C.,

273 authors reviewed the manuscript.

\section{Acknowledgements}

We would like to thank Editage (www.editage.co.kr) for English language editing.

1. Chamlin SL: The psychosocial burden of childhood atopic dermatitis. Dermatologic therapy 2006, 19(2):104-107.

2. Simpson EL, Bieber T, Guttman-Yassky E, Beck LA, Blauvelt A, Cork MJ, Silverberg JI, Deleuran M, Kataoka Y, Lacour JP et al: Two Phase 3 Trials of Dupilumab versus Placebo in Atopic Dermatitis. The New England journal of medicine 2016, 375(24):2335-2348.

3. Kantor R, Thyssen JP, Paller AS, Silverberg JI: Atopic dermatitis, atopic eczema, or eczema? A systematic review, meta-analysis, and recommendation for uniform use of 'atopic dermatitis'. Allergy 2016, 71(10):1480-1485.

4. Bergmann KC, Heinrich J, Niemann H: Current status of allergy prevalence in Germany: Position paper of the Environmental Medicine Commission of the Robert Koch Institute. Allergo journal international 2016, 25:6-10.

5. Saeki H, Tsunemi Y, Fujita H, Kagami S, Sasaki K, Ohmatsu H, Watanabe A, Tamaki K: Prevalence of atopic dermatitis determined by clinical examination in Japanese adults. The Journal of dermatology 2006, 33(11):817-819.

6. Silverberg JI, Hanifin JM: Adult eczema prevalence and associations with asthma and other health and demographic factors: a US population-based study. The Journal of allergy and clinical immunology 2013, 132(5):1132-1138.

7. Sidbury R, Davis DM, Cohen DE, Cordoro KM, Berger TG, Bergman JN, Chamlin SL, Cooper KD, Feldman SR, Hanifin JM et al: Guidelines of care for the management of atopic dermatitis: section 3. Management and treatment with phototherapy and systemic agents. Journal of the American Academy of Dermatology 2014, 71(2):327-349.

8. Deleuran M, Thaci D, Beck LA, de Bruin-Weller M, Blauvelt A, Forman S, Bissonnette R, Reich K, Soong W, Hussain I et al: Dupilumab shows long-term safety and efficacy in patients with moderate to severe atopic dermatitis enrolled in a phase 3 open-label extension study. Journal of the American Academy of Dermatology 2020, 82(2):377-388.

9. Ruzicka T, Hanifin JM, Furue M, Pulka G, Mlynarczyk I, Wollenberg A, Galus R, Etoh T, Mihara R, Yoshida $\mathrm{H}$ et al: Anti-Interleukin-31 Receptor A Antibody for Atopic Dermatitis. The New England journal of medicine 2017, 376(9):826-835.

310 responses. Blood 2005, 105(4):1815-1822. 
11. Le Blanc K, Tammik L, Sundberg B, Haynesworth SE, Ringden O: Mesenchymal stem cells inhibit and stimulate mixed lymphocyte cultures and mitogenic responses independently of the major histocompatibility complex. Scandinavian journal of immunology 2003, 57(1):11-20.

12. Figueroa FE, Carrion F, Villanueva S, Khoury M: Mesenchymal stem cell treatment for autoimmune diseases: a critical review. Biological research 2012, 45(3):269-277.

13. Kim HS, Lee JH, Roh KH, Jun HJ, Kang KS, Kim TY: Clinical Trial of Human Umbilical Cord BloodDerived Stem Cells for the Treatment of Moderate-to-Severe Atopic Dermatitis: Phase I/IIa Studies. Stem cells 2017, 35(1):248-255.

14. Shin TH, Kim HS, Choi SW, Kang KS: Mesenchymal Stem Cell Therapy for Inflammatory Skin Diseases: Clinical Potential and Mode of Action. International journal of molecular sciences 2017, 18(2).

15. Hanifin JM RG: Diagnostic features of atopic dermatitis. Acta Derm Venereol Suppl (Stockh) 1980(59):44-47.

16. Guttman-Yassky E, Brunner PM, Neumann AU, Khattri S, Pavel AB, Malik K, Singer GK, Baum D, Gilleaudeau P, Sullivan-Whalen $\mathrm{M}$ et al: Efficacy and safety of fezakinumab (an IL-22 monoclonal antibody) in adults with moderate-to-severe atopic dermatitis inadequately controlled by conventional treatments: A randomized, double-blind, phase 2a trial. Journal of the American Academy of Dermatology 2018, 78(5):872-881 e876.

17. Guttman-Yassky E, Krueger JG, Lebwohl MG: Systemic immune mechanisms in atopic dermatitis and psoriasis with implications for treatment. Experimental dermatology 2018, 27(4):409-417.

18. Esaki H, Brunner PM, Renert-Yuval Y, Czarnowicki T, Huynh T, Tran G, Lyon S, Rodriguez G, Immaneni $\mathrm{S}$, Johnson DB et al: Early-onset pediatric atopic dermatitis is TH2 but also TH17 polarized in skin. The Journal of allergy and clinical immunology 2016, 138(6):1639-1651.

19. Noda S, Suarez-Farinas M, Ungar B, Kim SJ, de Guzman Strong C, Xu H, Peng X, Estrada YD, Nakajima $\mathrm{S}$, Honda $\mathrm{T}$ et al: The Asian atopic dermatitis phenotype combines features of atopic dermatitis and psoriasis with increased TH17 polarization. The Journal of allergy and clinical immunology 2015, 136(5): 1254-1264.

20. Suarez-Farinas M, Dhingra N, Gittler J, Shemer A, Cardinale I, de Guzman Strong C, Krueger JG, Guttman-Yassky E: Intrinsic atopic dermatitis shows similar TH2 and higher TH17 immune activation compared with extrinsic atopic dermatitis. The Journal of allergy and clinical immunology 2013, 132(2):361-370.

21. Xiang T, Long H, He L, Han X, Lin K, Liang Z, Zhuo W, Xie R, Zhu B: Interleukin-17 produced by tumor microenvironment promotes self-renewal of $\mathrm{CD133}$ + cancer stem-like cells in ovarian cancer. Oncogene 2015, 34(2):165-176.

22. Lotti F, Jarrar AM, Pai RK, Hitomi M, Lathia J, Mace A, Gantt GA, Jr., Sukhdeo K, DeVecchio J, Vasanji A et al: Chemotherapy activates cancer-associated fibroblasts to maintain colorectal cancer-initiating cells by IL-17A. The Journal of experimental medicine 2013, 210(13):2851-2872. 
Figure 1

\section{A}
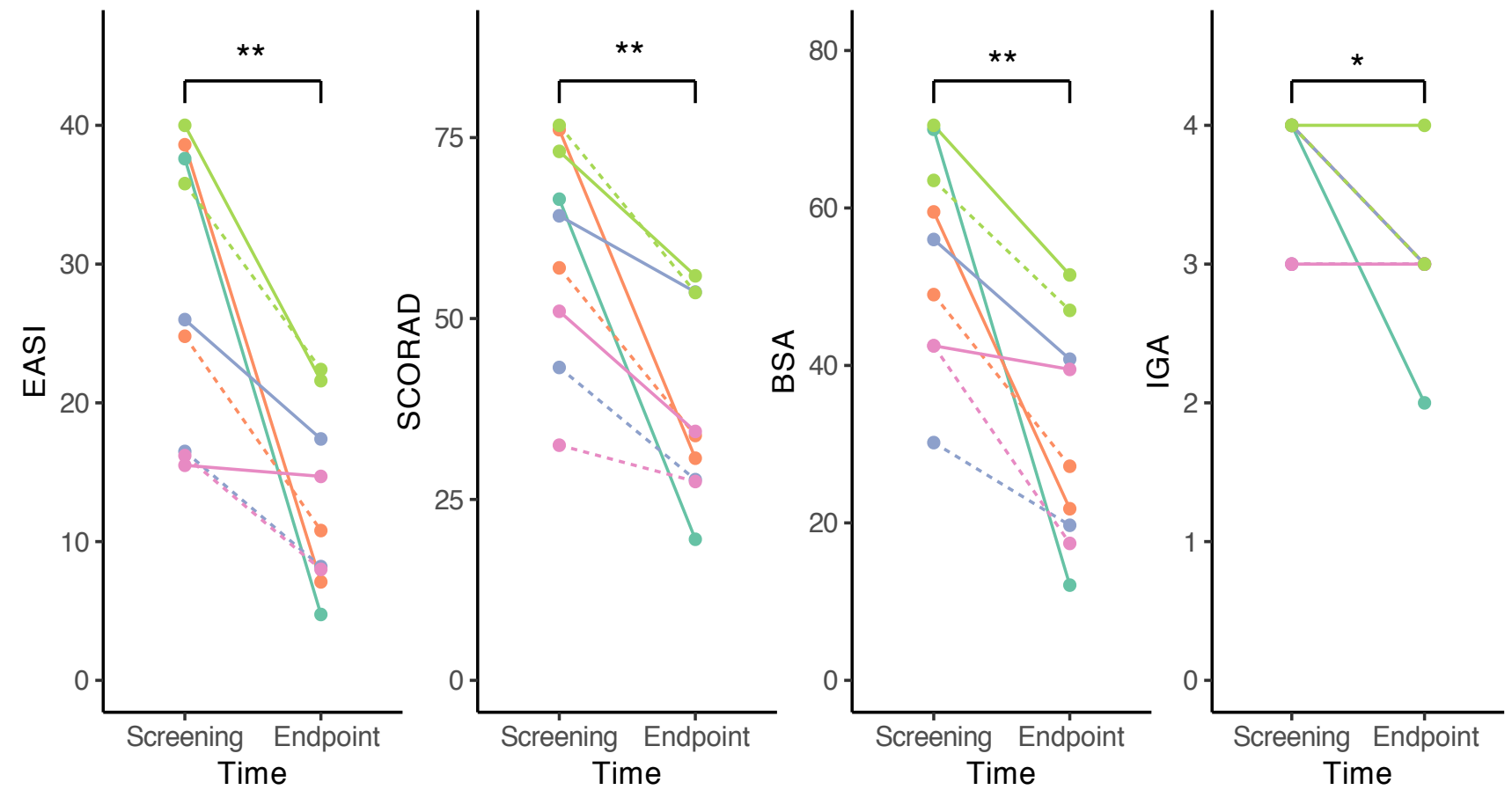

Treatment cycle

- 1st

.... 2nd

Patient ID

- S001

$\rightarrow$ S002

- S003

-๑ S004

- S S005

B

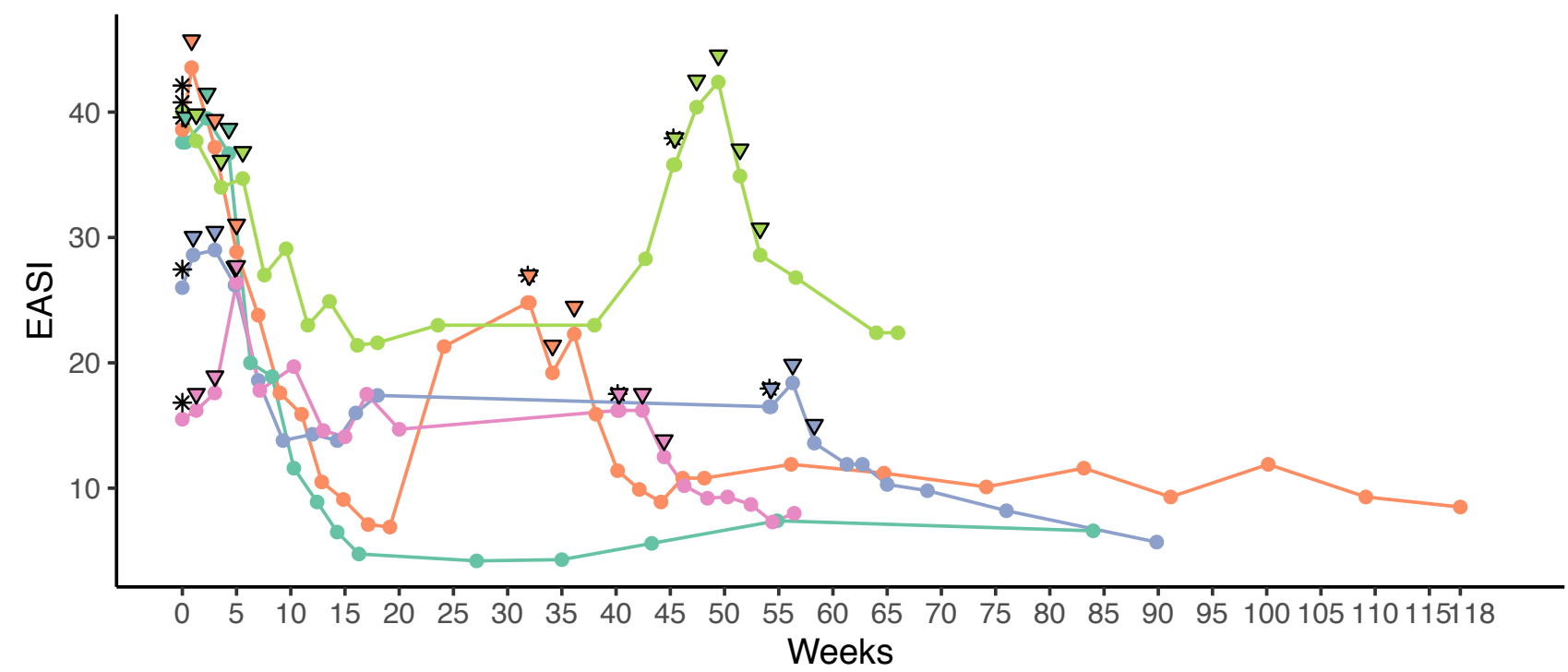

Patient

- S001

- S002

- S003

- S004

- S005

Status

* Screening

$\nabla$ Treatment 
Figure 2

A

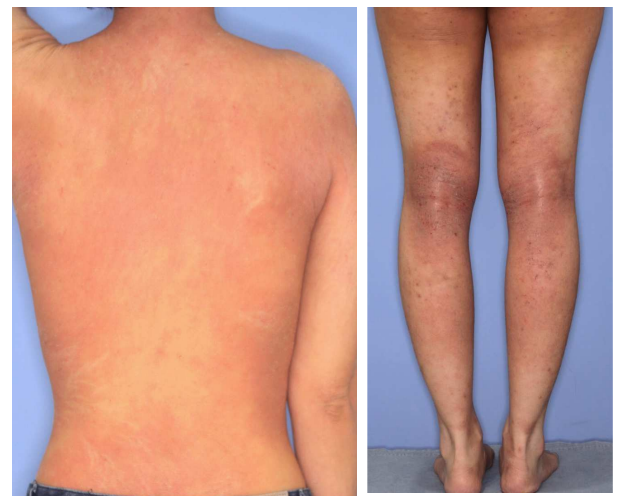

Cycle\#1 visit 2

Treatment \#1

B

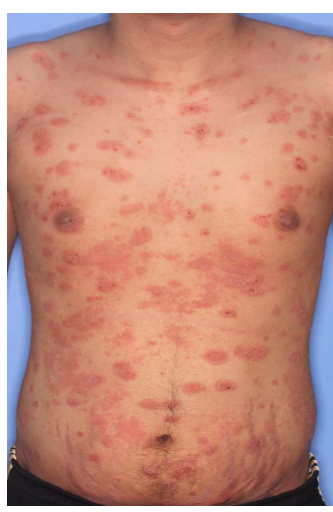

Cycle\#1 visit 1

Screening

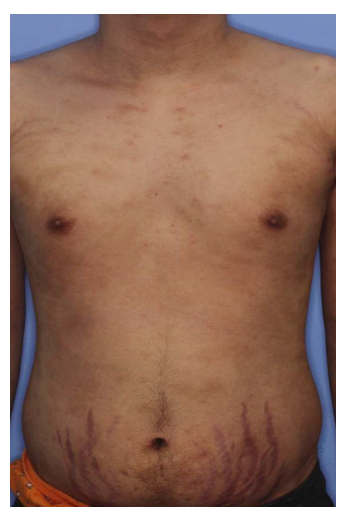

Cycle\#1 visit 10 f/u 17 weeks


Cycle\#1 visit 10 f/u 16 weeks


Cycle\#1 visit 12 f/u 35 weeks



Cycle\#2 visit 2 Treatment \#1

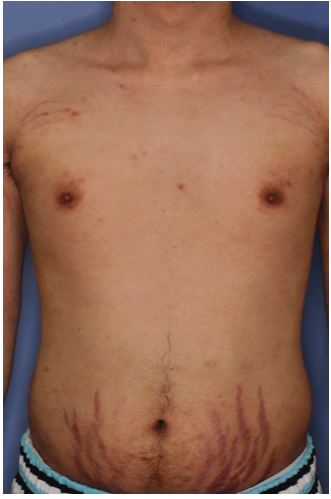

Cycle\#2 visit 8 f/u 12 weeks

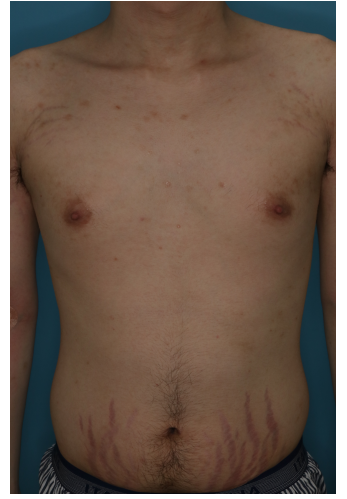

Cycle\#2 visit 18 f/u 86 weeks 


\section{Sup figure 1}
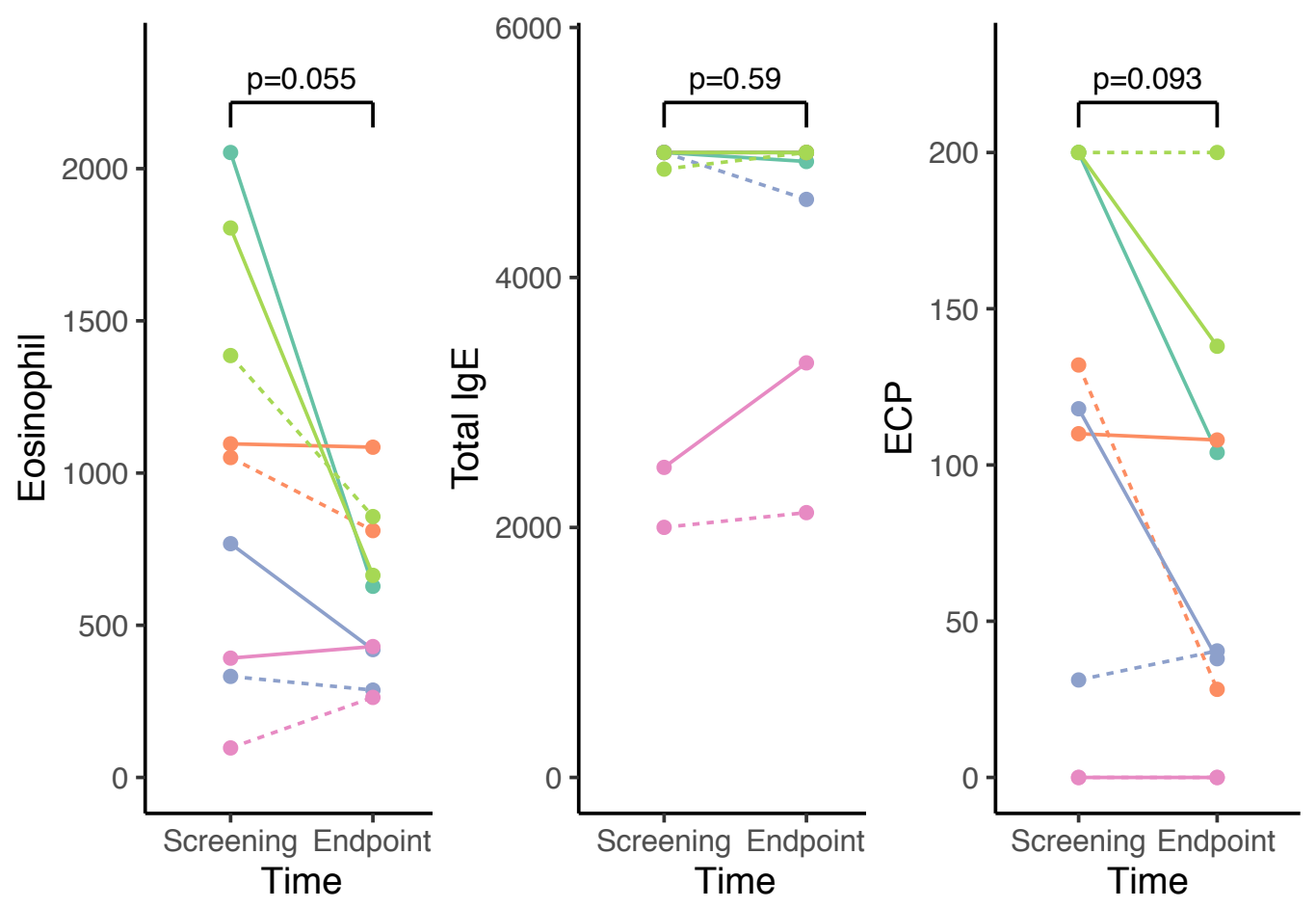

Treatment cycle

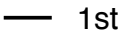

.... 2nd

Patient ID

- S001

- 5002

- 5003

- 5004

- 5005 


\section{Sup figure 2}

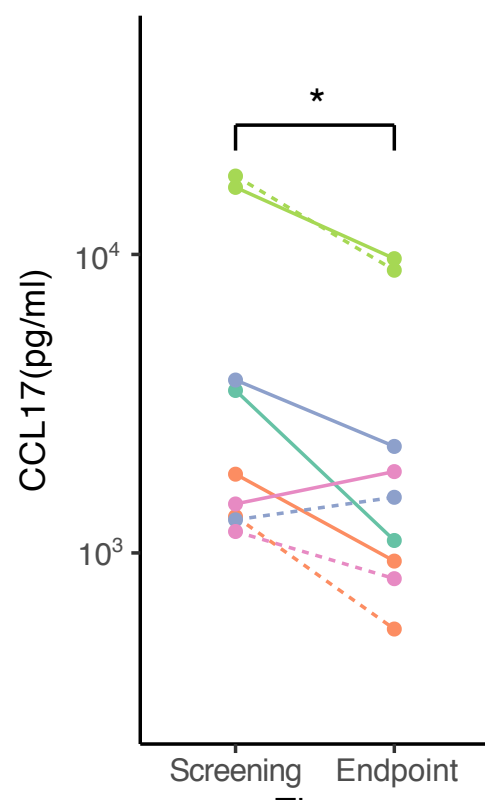

Time

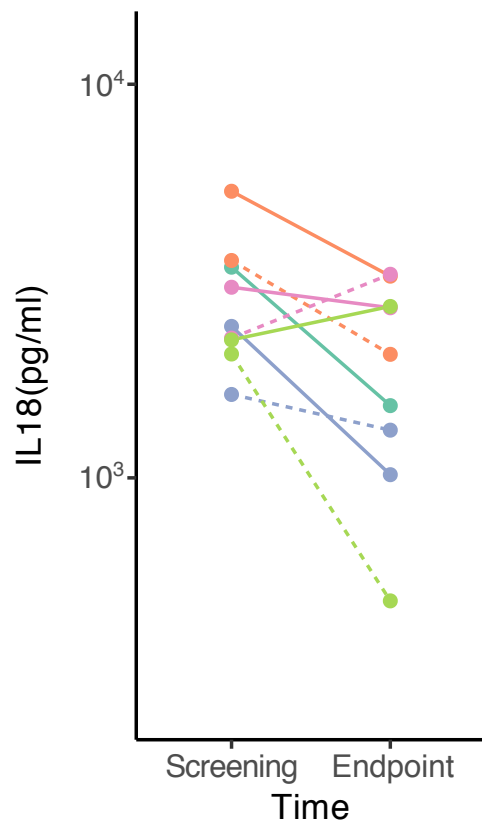



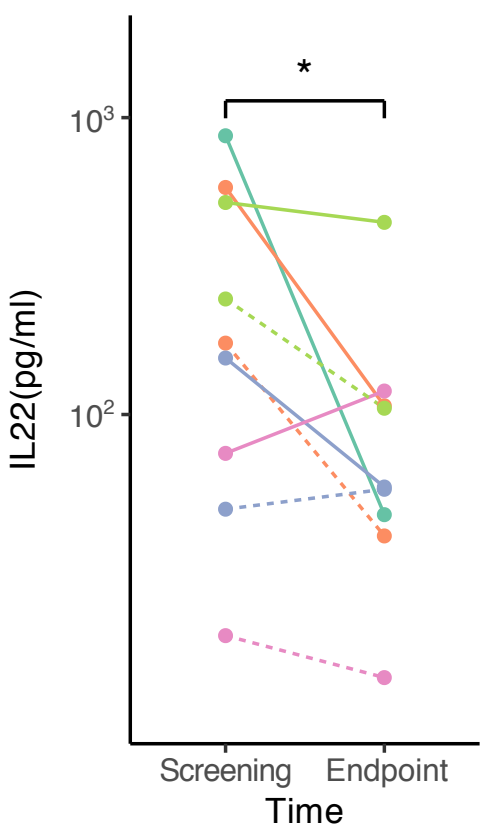

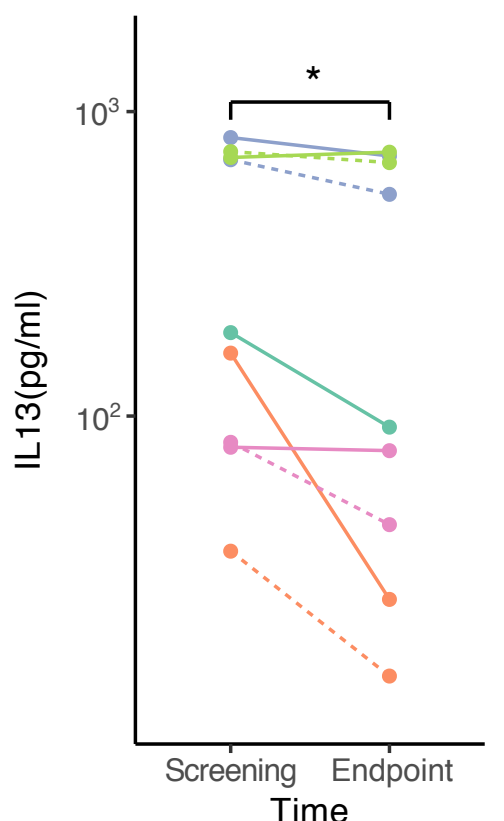

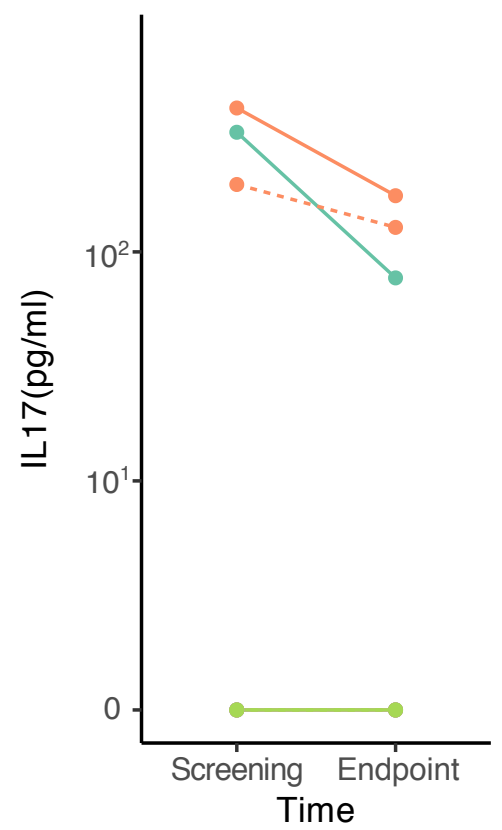

Patient

- S001

- S002

- 5003

- 5004

- $\mathrm{S} 005$

\section{Cycle}

- 1st

.... 2nd 
Supplementary table 1. Dilution factor of biomarkers

\begin{tabular}{cc}
\hline Biomarker & Dilution factor \\
\hline CCL-17 (TARC) & 10 \\
CCL-22 (MDC) & 20 \\
IL-13 & 2 \\
IL-17 & 1 \\
IL-18 & 20 \\
IL-22 & 1 \\
Total IgE & $500-1000$ \\
\hline
\end{tabular}


Supplementary table 2. Characteristics of the participants at baseline.

\begin{tabular}{ccc}
\hline Case & Sex/Age & Previous treatments \\
\hline 1 & F/24 & $\begin{array}{r}\text { Allergen-specific immunotherapy, Cyclosporine, Topical } \\
\text { corticosteroids, Topical calcineurin inhibitors }\end{array}$ \\
2 & M/21 & $\begin{array}{r}\text { Systemic steroids, Cyclosporine, Topical corticosteroids, Topical } \\
\text { calcineurin inhibitors }\end{array}$ \\
3 & F/29 & $\begin{array}{r}\text { Systemic steroids, Phototherapy, Cyclosporine, Topical } \\
\text { corticosteroids, Topical calcineurin inhibitors } \\
4\end{array}$ \\
5 M/20 & $\begin{array}{r}\text { Systemic steroids, Phototherapy, Cyclosporine, Topical } \\
\text { corticosteroids, Topical calcineurin inhibitors }\end{array}$ \\
5 & M/21 & $\begin{array}{r}\text { Systemic steroids, Phototherapy, Cyclosporine, Topical } \\
\text { corticosteroids, Topical calcineurin inhibitors }\end{array}$ \\
\hline
\end{tabular}

EASI: Eczema Area and Severity Index

SCORAD: Severity Scoring for Atopic Dermatitis 


\begin{tabular}{cc} 
EASI & SCORAD \\
37.6 & 66.5 \\
38.6 & 76.1 \\
26 & 64.2 \\
15.5 & 51 \\
40 & 73.1 \\
\hline
\end{tabular}


Supplementary table 3. Clinical response measures and biomarker levels

\begin{tabular}{|c|c|c|c|c|c|}
\hline Patient ID. & & Visit 1 & Visit 2 & Visit 3 & Visit 4 \\
\hline \multirow{10}{*}{ S001 } & & 2017.07.12 & 2017.07 .14 & 2017.07 .28 & 2017.08 .11 \\
\hline & & Sycle1_Screenil & Cycle1_Tx1 & Cycle1_Tx2 & Cycle1_Tx3 \\
\hline & MSCs cell-line ID & & A0408 D13 & A0106 D126 & A0106 D126 \\
\hline & BSA & 70 & 70 & 69 & 62.5 \\
\hline & EASI & 37.6 & 37.6 & 39.5 & 36.7 \\
\hline & SCORAD & 66.5 & 66.5 & 69.8 & 65.5 \\
\hline & IGA & 4 & 4 & 4 & 4 \\
\hline & Eosinophil count & 2053 & 2406 & 2503 & 2618 \\
\hline & Total $\lg \mathrm{E}$ & 5000 & 5000 & 5000 & 5000 \\
\hline & ECP & 200 & 200 & 200 & 200 \\
\hline \multirow{10}{*}{ S002 } & & 2017.11 .16 & 2017.11 .22 & 2017.12 .07 & 2017.12 .21 \\
\hline & & Cycle1_Screenil & Cycle1_Tx1 & Cycle1_Tx2 & Cycle1_Tx3 \\
\hline & MSCs cell-line ID & & A0106 D126 & A0106 D127 & A0106 D127 \\
\hline & BSA & 59.5 & 71.5 & 70.5 & 61.5 \\
\hline & EASI & 38.6 & 43.55 & 37.2 & 28.85 \\
\hline & SCORAD & 76.1 & 80.3 & 73.6 & 60.9 \\
\hline & IGA & 4 & 4 & 4 & 4 \\
\hline & Eosinophil count & 1096 & 1643 & 1469 & 780 \\
\hline & Total IgE & 5000 & - & 5000 & 5000 \\
\hline & ECP & 110 & - & 91.3 & 138 \\
\hline \multirow{10}{*}{ S003 } & & 2018.05 .02 & 2018.05 .09 & 2018.05 .23 & 2018.06 .05 \\
\hline & & Sycle1_Screenil & Cycle1_Tx1 & Cycle1_Tx2 & Cycle1_Tx3 \\
\hline & MSCs cell-line ID & & A0102 D201 & A0106 D126 & A0108 D203 \\
\hline & BSA & 56 & 63 & 61.3 & 58.3 \\
\hline & EASI & 26 & 28.6 & 29 & 26.2 \\
\hline & SCORAD & 64.2 & 69.1 & 68.76 & 65.66 \\
\hline & IGA & 4 & 4 & 4 & 4 \\
\hline & Eosinophil count & 768 & 1519 & 1513 & 825 \\
\hline & Total lgE & 5000 & - & 5000 & 5000 \\
\hline & ECP & 118 & - & 122 & 105 \\
\hline \multirow{8}{*}{ S004 } & \multirow{2}{*}{\multicolumn{2}{|c|}{$\begin{array}{c}2018.05 .15 \\
\text { Cycle1_Screenil }\end{array}$}} & 2018.05 .24 & 2018.06 .05 & 2018.06 .19 \\
\hline & & & Cycle1_Tx1 & Cycle1_Tx2 & Cycle1_Tx3 \\
\hline & MSCs cell-line ID & & A0106 D127 & A0106 D127 & A0106 D127 \\
\hline & BSA & 42.5 & 45.3 & 48.8 & 62 \\
\hline & EASI & 15.5 & 16.2 & 17.6 & 26.4 \\
\hline & SCORAD & 51 & 51.06 & 48.56 & 62.7 \\
\hline & IGA & 3 & 3 & 3 & 4 \\
\hline & Eosinophil count & 392 & 473 & 668 & 847 \\
\hline
\end{tabular}




\begin{tabular}{|c|c|c|c|c|c|}
\hline & Total lgE & 2481 & - & 2540 & 2514 \\
\hline & ECP & 0 & - & 0 & 0 \\
\hline \multirow{10}{*}{ S005 } & \multirow{3}{*}{\multicolumn{2}{|c|}{$\begin{array}{c}2018.05 .21 \\
\text { Cycle1_Screeni }\end{array}$}} & 2018.05 .30 & 2018.06 .15 & 2018.06 .29 \\
\hline & & & Cycle1_Tx1 & Cycle1_Tx2 & Cycle1_Tx3 \\
\hline & & & A0106 D127 & A0106 D127 & A0106 D127 \\
\hline & BSA & 70.5 & 70 & 69 & 68.5 \\
\hline & EASI & 40 & 37.7 & 34 & 34.7 \\
\hline & SCORAD & 73.1 & 68.5 & 73.8 & 64.8 \\
\hline & IGA & 4 & 4 & 4 & 4 \\
\hline & Eosinophil count & 1805 & 1813 & 2162 & 1383 \\
\hline & Total lgE & 5000 & - & 5000 & 5000 \\
\hline & ECP & 200 & - & 200 & 200 \\
\hline
\end{tabular}

BSA: Body Surface Area

EASI: Eczema Area and Severity Index

SCORAD: Severity Scoring for Atopic Dermatitis

IGA: Investigator Global Assessment

ECP: Eosinophil Cationic Protein

Tx: Treatment

FU: Follow-up 


\begin{tabular}{|c|c|c|c|c|c|}
\hline Visit 5 & Visit 6 & Visit 7 & Visit 8 & Visit 9 & Visit 10 \\
\hline 2017.08 .25 & 2017.09 .08 & 2017.09 .22 & 2017.10 .07 & 2017.10 .20 & 2017.11 .03 \\
\hline Cycle1_FU & Cycle1_FU & Cycle1_FU & Cycle1_FU & Cycle1_FU & Cycle1_FU \\
\hline 46.5 & 34.9 & 23.5 & 20.1 & 18.1 & 12.1 \\
\hline 20 & 18.9 & 11.6 & 8.9 & 6.5 & 4.75 \\
\hline 52.3 & 43.48 & 32.2 & 23.52 & 24.12 & 19.5 \\
\hline 3 & 3 & 3 & 3 & 2 & 2 \\
\hline 1998 & 1505 & - & 666 & - & 628 \\
\hline 5000 & - & - & - & - & 4928 \\
\hline 200 & - & - & - & - & 104 \\
\hline 2018.01.04 & 2018.01.18 & 2018.02 .01 & 2018.02 .14 & 2018.02.28 & 2018.03.16 \\
\hline Cycle1_FU & Cycle1_FU & Cycle1_FU & Cycle1_FU & Cycle1_FU & Cycle1_FU \\
\hline 52.5 & 43 & 40 & 27.1 & 25.6 & 21.8 \\
\hline 23.8 & 17.6 & 15.9 & 10.5 & 9.1 & 7.1 \\
\hline 55.1 & 40.8 & 40.6 & 32.9 & 30.6 & 30.7 \\
\hline 4 & 3 & 3 & 3 & 3 & 3 \\
\hline 696 & 749 & - & 732 & - & 1085 \\
\hline 5000 & - & - & - & - & 5000 \\
\hline 131 & - & - & - & - & 108 \\
\hline 2018.06 .20 & 2018.07 .06 & 2018.07 .25 & 2018.08 .10 & 2018.08 .22 & 2018.09 .05 \\
\hline Cycle1_FU & Cycle1_FU & Cycle1_FU & Cycle1_FU & Cycle1_FU & Cycle1_FU \\
\hline 41.3 & 32.8 & 35.4 & 31 & 32 & 40.8 \\
\hline 18.6 & 13.8 & 14.3 & 13.8 & 16 & 17.4 \\
\hline 48.76 & 42.56 & 48.98 & 48.2 & 50.2 & 53.66 \\
\hline 3 & 3 & 3 & 3 & 3 & 3 \\
\hline 741 & 406 & - & 672 & - & 420 \\
\hline 5000 & - & - & - & - & 5000 \\
\hline 73.2 & - & - & - & - & 38 \\
\hline 2018.07 .04 & 2018.07 .26 & 2018.08 .14 & 2018.08 .28 & 2018.09 .11 & 2018.10 .02 \\
\hline Cycle1_FU & Cycle1_FU & Cycle1_FU & Cycle1_FU & Cycle1_FU & Cycle1_FU \\
\hline 43.4 & 51.3 & 42.1 & 40.9 & 40.4 & 39.5 \\
\hline 17.8 & 19.7 & 14.6 & 14.1 & 17.5 & 14.7 \\
\hline 41.68 & 42.96 & 37.42 & 35.38 & 37.28 & 34.4 \\
\hline 3 & 3 & 3 & 3 & 3 & 3 \\
\hline 684 & 781 & - & 318 & - & 430 \\
\hline
\end{tabular}




\begin{tabular}{cccccc}
2794 & - & - & - & - & 3317 \\
0 & - & - & - & - & 0 \\
\hline 2018.07 .13 & 2018.07 .27 & 2018.08 .10 & 2018.08 .24 & 2018.09 .11 & 2018.09 .24 \\
Cycle1_FU & Cycle1_FU & Cycle1_FU & Cycle1_FU & Cycle1_FU & Cycle1_FU \\
& & & & & \\
60 & 63 & 56 & 58 & 47 & 51.5 \\
27 & 29.1 & 23 & 24.9 & 21.4 & 21.6 \\
61.8 & 56.7 & 57.7 & 57.4 & 49.5 & 55.9 \\
4 & 4 & 4 & 4 & 4 & 4 \\
896 & 944 & - & 889 & - & 664 \\
5000 & - & - & - & - & 5000 \\
200 & - & - & - & - & 138 \\
\hline
\end{tabular}




\begin{tabular}{|c|c|c|c|c|c|}
\hline Visit 11 & Visit 12 & Visit 13 & Visit 14 & Visit 15 & Visit 16 \\
\hline 2018.01 .18 & 2018.03 .14 & 2018.05 .11 & 2018.07 .31 & 2019.02 .20 & \\
\hline FU & FU & FU & FU & FU & \\
\hline 11.3 & 12.5 & 18 & 15 & 15.5 & \\
\hline 4.2 & 4.3 & 5.6 & 7.4 & 6.6 & \\
\hline 18.2 & 19.3 & 28.6 & 38.3 & 30.9 & \\
\hline 1 & 1 & 1 & 2 & 1 & \\
\hline 521 & 474 & 427.8 & 650 & 733 & \\
\hline 5000 & 4442 & 5000 & 5000 & 5000 & \\
\hline 125 & 74.4 & 88.2 & 73.4 & 102 & \\
\hline 2018.03 .30 & 2018.05 .04 & 2018.06.27 & 2018.06 .28 & 2018.07 .13 & 2018.07.27 \\
\hline \multirow[t]{2}{*}{ FU } & FU & /cle2_Screeniı & Cycle2_Tx1 & Cycle2_Tx2 & Cycle2_Tx3 \\
\hline & & & A0108 D203 & A0102 D201 & A0106 D104 \\
\hline 19.4 & 44 & 49 & 49 & 44.1 & 41.2 \\
\hline 6.9 & 21.3 & 24.8 & 24.8 & 19.2 & 22.3 \\
\hline 30.4 & 65.3 & 57 & 57 & 41.82 & 46.64 \\
\hline \multirow[t]{4}{*}{3} & 4 & 4 & 4 & 4 & 4 \\
\hline & - & 1051 & 1290 & 982 & 668 \\
\hline & - & 5000 & - & 5000 & 5000 \\
\hline & - & 132 & - & 135 & 55.6 \\
\hline 2019.05 .16 & 2019.05 .17 & 2019.05 .31 & 2019.06 .14 & 2019.07 .05 & 2019.07 .15 \\
\hline \multirow[t]{2}{*}{ /cle2_Screenil } & Cycle2_Tx1 & Cycle2_Tx2 & Cycle2_Tx3 & Cycle2_FU & Cycle2_FU \\
\hline & A0106 D127 & A0106 D127 & A0106 D127 & & \\
\hline 30.2 & 30.2 & 33.1 & 30 & 28.5 & 27.6 \\
\hline 16.5 & 16.5 & 18.4 & 13.6 & 11.9 & 11.9 \\
\hline 43.24 & 43.24 & 51.62 & 39.1 & 38.4 & 37.72 \\
\hline 3 & 3 & 3 & 3 & 3 & 3 \\
\hline 332 & - & 362 & 312 & 386 & 258 \\
\hline 5000 & - & 4457 & 4638 & 4698 & - \\
\hline 31.2 & - & 39.7 & 63.6 & 63.6 & - \\
\hline 2019.02 .20 & 2019.02 .21 & 2019.03 .08 & 2019.03 .22 & 2019.04 .04 & 2019.04 .19 \\
\hline \multirow[t]{2}{*}{ /cle2_Screenil } & Cycle2_Tx1 & Cycle2_Tx2 & Cycle2_Tx3 & Cycle2_FU & Cycle2_FU \\
\hline & A0106 D127 & A0106 D127 & A0106 D127 & & \\
\hline 42.5 & 42.5 & 42 & 35.5 & 29 & 27 \\
\hline 16.2 & 16.2 & 16.2 & 12.5 & 10.2 & 9.2 \\
\hline 32.5 & 32.5 & 34.5 & 29.1 & 28.5 & 28.8 \\
\hline 3 & 3 & 3 & 3 & 3 & 3 \\
\hline 97 & 97 & 227 & 170 & 101 & 187 \\
\hline
\end{tabular}




\begin{tabular}{cccccc}
2001 & 2001 & 1905 & 1920 & 1880 & - \\
0 & 0 & 0 & 0 & 0 & - \\
\hline 2018.11 .02 & 2019.02 .11 & 2019.03 .16 & 2019.04 .03 & 2019.04 .04 & 2019.04 .18 \\
FU & FU & FU & /cle2_Screenil & Cycle2_Tx1 & Cycle2_Tx2 \\
& & & & A0106 D126 & A0106 D126 \\
- & - & - & 63.5 & 63.5 & 68.5 \\
23 & 23 & 28.3 & 35.8 & 35.8 & 40.4 \\
66.7 & 55.7 & 71.4 & 76.7 & 76.7 & 77.9 \\
- & - & - & 4 & 4 & 4 \\
- & - & - & 1386 & 1303 & 1518 \\
- & - & - & 4867 & - & 5000 \\
- & - & - & 200 & - & 200 \\
\hline
\end{tabular}




\begin{tabular}{llllll}
\hline Visit 17 & Visit 18 & Visit 19 & Visit 20 & Visit 21 & Visit 22 \\
\hline
\end{tabular}

\begin{tabular}{|c|c|c|c|c|c|}
\hline 2018.08 .10 & 2018.08 .24 & 2018.09 .07 & 2018.09 .21 & 2018.10 .05 & 2018.10 .19 \\
\hline Cycle2_FU & Cycle2_FU & Cycle2_FU & Cycle2_FU & Cycle2_FU & Cycle2_FU \\
\hline 36.3 & 28.6 & 27.1 & 24.2 & 26.2 & 27.2 \\
\hline 15.9 & 11.4 & 9.9 & 8.9 & 10.8 & 10.8 \\
\hline 46.36 & 39.22 & 30.82 & 29.44 & 34.04 & 33.84 \\
\hline 3 & 3 & 3 & 3 & 3 & 3 \\
\hline 763 & 819 & - & 634 & - & 811 \\
\hline 5000 & - & - & - & - & 5000 \\
\hline 108 & - & - & - & - & 28.2 \\
\hline 2019.07.31 & 2019.08.26 & 2019.10.16 & 2020.1 .21 & & \\
\hline Cycle2_FU & Cycle2_FU & Cycle2_FU & FU & & \\
\hline 25.4 & 21.8 & 19.7 & - & & \\
\hline 10.3 & 9.8 & 8.2 & 5.7 & & \\
\hline 34.68 & 33.36 & 27.74 & - & & \\
\hline 3 & 3 & 3 & - & & \\
\hline - & 291 & 287 & - & & \\
\hline - & - & 4625 & - & & \\
\hline- & - & 40.5 & - & & \\
\hline 2019.05.02 & 2019.05 .17 & 2019.05.31 & 2019.06 .14 & & \\
\hline Cycle2_FU & Cycle2_FU & Cycle2_FU & Cycle2_FU & & \\
\hline 21.8 & 21.5 & 17.8 & 17.4 & & \\
\hline 9.3 & 8.7 & 7.3 & 8 & & \\
\hline 28.46 & 30.2 & 31.16 & 27.48 & & \\
\hline 3 & 3 & 3 & 3 & & \\
\hline - & 197 & - & 263 & & \\
\hline
\end{tabular}




\begin{tabular}{cccccc}
- & - & - & 2119 & & \\
- & - & - & 0 & & \\
\hline 2019.05 .02 & 2019.05 .16 & 2019.05 .29 & 2019.06 .21 & 2019.06 .28 & 2019.08 .12 \\
Cycle2_Tx3 & Cycle2_Tx4 & Cycle2_Tx5 & Cycle2_FU & Cycle2_FU & Cycle2_FU \\
A0106 D126 & A0106 D127 & A0106 D127 & & & \\
70.5 & 59.5 & 54.5 & 54 & - & 50.8 \\
42.4 & 34.9 & 28.6 & 26.8 & - & 22.4 \\
77.8 & 72.7 & 70.4 & 71.1 & - & 52.26 \\
4 & 4 & 4 & 4 & - & 3 \\
1723 & 1342 & 1184 & 758 & 1058 & 848 \\
5000 & 5000 & 5000 & 5000 & - & - \\
200 & 200 & 200 & 200 & - & - \\
\hline
\end{tabular}




\begin{tabular}{llllll}
\hline Visit 23 & Visit 24 & Visit 25 & Visit 26 & Visit 27 & Visit 28 \\
\hline
\end{tabular}

\begin{tabular}{cccccc}
\hline $\begin{array}{c}2018.12 .14 \\
\text { FU }\end{array}$ & $\begin{array}{c}2019.02 .12 \\
\text { FU }\end{array}$ & $\begin{array}{c}2019.04 .19 \\
\text { FU }\end{array}$ & $\begin{array}{c}2019.06 .21 \\
\text { FU }\end{array}$ & $\begin{array}{c}2019.08 .16 \\
\text { FU }\end{array}$ & $\begin{array}{c}2019.10 .18 \\
\text { FU }\end{array}$ \\
24.2 & 20.6 & - & - & - & - \\
11.9 & 11.2 & 10.1 & 11.6 & 9.3 & 11.9 \\
36.74 & 28.12 & - & - & - & - \\
2 & 2 & - & - & - & - \\
876 & 910 & - & 620 & 615 & 614 \\
5000 & 5000 & - & 5000 & 5000 & - \\
105 & 106 & - & 78.6 & - & - \\
\hline
\end{tabular}


2019.08.26

Cycle2_FU

$$
\begin{gathered}
47 \\
22.4 \\
53.6 \\
3 \\
857 \\
5000 \\
200
\end{gathered}
$$




\section{Visit 29 Visit 30}

\begin{tabular}{cc}
\hline 2019.12 .20 & 2020.02 .19 \\
FU & FU \\
& \\
- & - \\
9.3 & 8.5 \\
- & - \\
- & - \\
- & 602 \\
- & 5000 \\
- & - \\
\hline
\end{tabular}




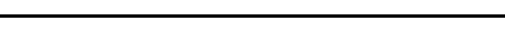


Supplementary table 4. Levels of cytokine biomarkers measured by enzyme-linked imr

\begin{tabular}{|c|c|c|c|c|}
\hline Biomarkers & Patient ID. & Cycle & Visit 1 & Visit 3 \\
\hline CCL17 (pg/ml) & S001 & 1 st & 3503 & 3262 \\
\hline CCL17 (pg/ml) & S002 & 1st & 1836 & 1430 \\
\hline CCL17 (pg/ml) & S002 & 2nd & 1324 & 969 \\
\hline CCL17 (pg/ml) & S003 & $1 \mathrm{st}$ & 3796 & 2619 \\
\hline CCL17 (pg/ml) & S003 & 2nd & 1291 & 1542 \\
\hline CCL17 (pg/ml) & S004 & 1st & 1459 & 2674 \\
\hline CCL17 (pg/ml) & S004 & 2nd & 1180 & 1366 \\
\hline CCL17 (pg/ml) & S005 & $1 \mathrm{st}$ & 16782 & 14449 \\
\hline CCL17 (pg/ml) & S005 & 2nd & 18314 & 17870 \\
\hline CCL22 (pg/ml) & S001 & $1 \mathrm{st}$ & 1592 & 1997 \\
\hline CCL22 (pg/ml) & S002 & $1 \mathrm{st}$ & 5865 & 6923 \\
\hline CCL22 (pg/ml) & S002 & 2nd & 4644 & 2290 \\
\hline CCL22 (pg/ml) & S003 & $1 \mathrm{st}$ & 14773 & 14639 \\
\hline CCL22 (pg/ml) & S003 & 2nd & 13583 & 15787 \\
\hline CCL22 (pg/ml) & S004 & $1 \mathrm{st}$ & 2777 & 3494 \\
\hline CCL22 (pg/ml) & S004 & 2nd & 2166 & 3084 \\
\hline CCL22 (pg/ml) & S005 & $1 \mathrm{st}$ & 3358 & 2330 \\
\hline CCL22 (pg/ml) & S005 & 2nd & 1154 & 1085 \\
\hline IL13 (pg/ml) & S001 & $1 \mathrm{st}$ & 188 & 191 \\
\hline IL13 (pg/ml) & S002 & 1 st & 161 & 158 \\
\hline IL13 (pg/ml) & S002 & 2nd & 36 & 23 \\
\hline IL13 (pg/ml) & S003 & $1 \mathrm{st}$ & 822 & 747 \\
\hline IL13 (pg/ml) & S003 & 2nd & 695 & 742 \\
\hline IL13 (pg/ml) & S004 & $1 \mathrm{st}$ & 79 & 131 \\
\hline IL13 (pg/ml) & S004 & 2nd & 82 & 86 \\
\hline IL13 (pg/ml) & S005 & $1 \mathrm{st}$ & 707 & 728 \\
\hline IL13 (pg/ml) & S005 & 2nd & 739 & 688 \\
\hline IL17 (pg/ml) & S001 & $1 \mathrm{st}$ & 333 & 236 \\
\hline IL17 (pg/ml) & S002 & 1 st & 425 & 329 \\
\hline IL17 (pg/ml) & S002 & 2nd & 197 & 164 \\
\hline IL17 (pg/ml) & S003 & $1 \mathrm{st}$ & 0 & 0 \\
\hline IL17 (pg/ml) & S003 & 2nd & 0 & 0 \\
\hline IL17 (pg/ml) & S004 & $1 \mathrm{st}$ & 0 & 0 \\
\hline IL17 (pg/ml) & S004 & 2nd & 0 & 0 \\
\hline IL17 (pg/ml) & S005 & $1 \mathrm{st}$ & 0 & 0 \\
\hline IL17 (pg/ml) & S005 & 2nd & 0 & 0 \\
\hline IL18 (pg/ml) & S001 & $1 \mathrm{st}$ & 3430 & 4004 \\
\hline IL18 (pg/ml) & S002 & 1st & 5348 & 3866 \\
\hline
\end{tabular}




\begin{tabular}{|c|c|c|c|c|}
\hline IL18 (pg/ml) & S002 & 2nd & 3567 & 2819 \\
\hline IL18 (pg/ml) & S003 & $1 \mathrm{st}$ & 2426 & 1835 \\
\hline IL18 (pg/ml) & S003 & 2nd & 1629 & 1637 \\
\hline IL18 (pg/ml) & S004 & $1 \mathrm{st}$ & 3050 & 3044 \\
\hline IL18 (pg/ml) & S004 & 2nd & 2265 & 2838 \\
\hline IL18 (pg/ml) & S005 & $1 s t$ & 2242 & 2444 \\
\hline IL18 (pg/ml) & S005 & 2nd & 2064 & 3112 \\
\hline IL22 (pg/ml) & S001 & $1 s t$ & 869 & 940 \\
\hline IL22 (pg/ml) & S002 & $1 s t$ & 582 & 570 \\
\hline IL22 (pg/ml) & S002 & 2nd & 174 & 75 \\
\hline IL22 (pg/ml) & S003 & $1 s t$ & 155 & 160 \\
\hline IL22 (pg/ml) & S003 & 2nd & 48 & 55 \\
\hline IL22 (pg/ml) & S004 & $1 \mathrm{st}$ & 74 & 217 \\
\hline IL22 (pg/ml) & S004 & 2nd & 18 & 30 \\
\hline IL22 (pg/ml) & S005 & $1 s t$ & 518 & 453 \\
\hline IL22 (pg/ml) & S005 & 2nd & 245 & 259 \\
\hline $\lg E(k U / L)$ & S001 & $1 s t$ & 17832 & 11064 \\
\hline $\lg E(k U / L)$ & S002 & $1 s t$ & 141639 & 130312 \\
\hline $\lg E(k U / L)$ & S002 & 2nd & 77212 & 78422 \\
\hline $\lg E(k U / L)$ & S003 & $1 s t$ & 11129 & 9517 \\
\hline $\lg E(k U / L)$ & S003 & 2nd & 7828 & 6331 \\
\hline $\lg E(k U / L)$ & S004 & $1 s t$ & 29301 & 28370 \\
\hline $\lg E(k U / L)$ & S004 & 2nd & 22014 & 24931 \\
\hline $\lg E(k U / L)$ & S005 & $1 s t$ & 21314 & 12085 \\
\hline $\lg E(k U / L)$ & S005 & 2nd & 7541 & 9635 \\
\hline
\end{tabular}


nunosorbent assay.

\begin{tabular}{|c|c|c|c|c|}
\hline Visit 4 & Visit 5 & Visit 6 & Visit 8 & Visit 10 \\
\hline 2522 & 2433 & 2438 & 1227 & 1101 \\
\hline 1110 & 1050 & 1001 & 939 & 939 \\
\hline 827 & 785 & 636 & 643 & 556 \\
\hline 3451 & 2436 & 1617 & 1362 & 2275 \\
\hline 1354 & 1297 & 588 & 1476 & 1536 \\
\hline 4849 & 3786 & 6491 & 1683 & 1873 \\
\hline 1408 & 859 & 904 & 1159 & 820 \\
\hline 8783 & 6011 & 10604 & 12703 & 9684 \\
\hline 17555 & 14128 & 9323 & 10293 & 8856 \\
\hline 2072 & 952 & 980 & 442 & 402 \\
\hline 2737 & 2994 & 2382 & 2318 & 2318 \\
\hline 1936 & 1902 & 1795 & 1770 & 1624 \\
\hline 13484 & 12669 & 12286 & 12548 & 12768 \\
\hline 15206 & 13640 & 13221 & 12307 & 15536 \\
\hline 3556 & 3076 & 4127 & 2970 & 2707 \\
\hline 3201 & 2745 & 2698 & 2756 & 2536 \\
\hline 1724 & 1014 & 1082 & 1442 & 1142 \\
\hline 1123 & 988 & 925 & 894 & 1069 \\
\hline 170 & 159 & 133 & 119 & 92 \\
\hline 81 & 81 & 63 & 56 & 25 \\
\hline 22 & 19 & 19 & 18 & 14 \\
\hline 734 & 678 & 691 & 700 & 715 \\
\hline 737 & 662 & 635 & 610 & 535 \\
\hline 88 & 69 & 58 & 72 & 77 \\
\hline 78 & 89 & 75 & 66 & 44 \\
\hline 691 & 643 & 676 & 660 & 736 \\
\hline 701 & 676 & 687 & 677 & 680 \\
\hline 126 & 119 & 76 & 36 & 77 \\
\hline 249 & 137 & 128 & 183 & 176 \\
\hline 158 & 144 & 124 & 139 & 128 \\
\hline 0 & 0 & 0 & 0 & 0 \\
\hline 0 & 0 & 0 & 0 & 0 \\
\hline 0 & 0 & 0 & 0 & 0 \\
\hline 0 & 0 & 0 & 0 & 0 \\
\hline 0 & 0 & 0 & 0 & 0 \\
\hline 0 & 0 & 0 & 0 & 0 \\
\hline 2836 & 2431 & 2307 & 1635 & 1526 \\
\hline 3238 & 2617 & 2672 & 2758 & 3255 \\
\hline
\end{tabular}




\begin{tabular}{ccccc}
2620 & 2415 & 2328 & 1841 & 2060 \\
2504 & 2276 & 2040 & 1715 & 1019 \\
2449 & 1989 & 1602 & 1538 & 1322 \\
2175 & 3201 & 3363 & 2633 & 2705 \\
3517 & 3638 & 2785 & 3279 & 3291 \\
608 & 924 & 2092 & 749 & 2726 \\
1193 & 809 & 886 & 855 & 487 \\
644 & 413 & 159 & 64 & 46 \\
209 & 268 & 69 & 95 & 107 \\
82 & 74 & 96 & 76 & 39 \\
148 & 75 & 68 & 56 & 57 \\
52 & 67 & 73 & 59 & 56 \\
171 & 152 & 226 & 69 & 120 \\
26 & 33 & 19 & 34 & 13 \\
599 & 223 & 274 & 239 & 444 \\
287 & 135 & 168 & 121 & 105 \\
14923 & 12085 & 10157 & 8010 & 5778 \\
118280 & 111065 & 92940 & 84192 & 72759 \\
79512 & 76814 & 73151 & 62677 & 56796 \\
9682 & 9875 & 12399 & 9312 & 13001 \\
7997 & 5498 & 6400 & 4663 & 7021 \\
30677 & 42127 & 38687 & 41200 & 42840 \\
28147 & 30584 & 23737 & 24960 & 32034 \\
11238 & 17196 & 19299 & 15163 & 10921 \\
14989 & 15782 & 12507 & 14440 & 7665 \\
\hline
\end{tabular}




\begin{tabular}{ccccc}
\hline Visit 11 & Visit 12 & Visit 13 & Visit 14 & Visit 15 \\
\hline 0 & 0 & 114 & 2 & 0
\end{tabular}

$418 \quad 343$

$4772 \quad 7448$

$\begin{array}{lllll}382 & 379 & 447 & 440 & 462\end{array}$

$964 \quad 806$

$912 \quad 888$

$\begin{array}{lllll}90 & 83 & 72 & 88 & 105\end{array}$

1920

$758 \quad 803$

$\begin{array}{lllll}66 & 53 & 66 & 56 & 45\end{array}$

$120 \quad 116$

$0 \quad 0$

$\begin{array}{lllll}1736 & 1387 & 1713 & 1490 & 1667\end{array}$


$1714 \quad 1801$

$443 \quad 622$

$46 \quad 35$

50

31

46

32

26

96

87

3545

3238

3664

4747

5740

$49027 \quad 41806$ 
(Emergency Treatment Protocol)

Clinical Trial for Emergency use Investigating the Efficacy and Safety of Allogeneic Bone Marrow-derived Mesenchymal Stem Cells for the Treatment of Moderate-to-Severe Atopic Dermatitis in Adult patient 


\section{Clinical Protocol}

\begin{tabular}{|c|c|}
\hline Protocol Number : & SCM-CGH-01 \\
\hline Protocol Version : & 2.0 \\
\hline Study Drug : & SCM-CGH \\
\hline Title : & $\begin{array}{l}\text { Clinical trial for Emergency use Investigating the Efficacy } \\
\text { and Safety of Allogeneic Bone Marrow-derived } \\
\text { Mesenchymal Stem Cells for the Treatment of Moderate-to- } \\
\text { Severe Atopic dermatitis in Adult patient }\end{array}$ \\
\hline Study Phase : & Emergency Use \\
\hline Study Director : & $\begin{array}{l}\text { Jeonghyun Shin, M.D., Ph.D. } \\
\text { Department of Dermatology } \\
\text { Inha University Hospital } \\
\text { College of Medicine, Incheon, South Korea }\end{array}$ \\
\hline Study Duration : & Within 24 months from the approval of clinical protocol \\
\hline
\end{tabular}


$\square$ Protocol Synopsis

\begin{tabular}{|c|c|}
\hline Title & $\begin{array}{l}\text { Clinical trial for Emergency use Investigating the Efficacy and Safety of } \\
\text { Allogeneic Bone Marrow-derived Mesenchymal Stem Cells for the } \\
\text { Treatment of Moderate-to-Severe Atopic dermatitis in Adult patient }\end{array}$ \\
\hline $\begin{array}{l}\text { Study Site } \\
\text { \& Director }\end{array}$ & $\begin{array}{l}\text { - Study Site } \\
\text { Department of Dermatology, Inha University Hospital } \\
\text { College of Medicine, Incheon, South Korea } \\
\text { - Study Director } \\
\text { Jeonghyun Shin, M.D., Ph.D. }\end{array}$ \\
\hline Study Duration & Within 24 months from the approval of clinical protocol \\
\hline $\begin{array}{l}\text { Study } \\
\text { Objectives }\end{array}$ & $\begin{array}{l}\text { The objective in this trial is to demonstrate the efficacy and safety of } \\
\text { multiple doses of SCM-CGH in adult patient with moderate-to-severe } \\
\text { AD }\end{array}$ \\
\hline $\begin{array}{l}\text { Study Phase } \\
\text { and Design }\end{array}$ & $\begin{array}{l}\text { This is a single-center, open-labeled study to evaluate the efficacy and } \\
\text { safety of multiple doses of allogeneic mesenchymal stem cells derived } \\
\text { from bone marrow in adults with moderate-to-severe atopic dermatitis. } \\
\text { The study is } 16 \text { weeks (4-week treatment period and 12-week follow- } \\
\text { up). }\end{array}$ \\
\hline Study Drug & $\begin{array}{l}\text { SCM-CGH } \\
\text { (allogeneic mesenchymal stem cells derived from bone marrow) }\end{array}$ \\
\hline $\begin{array}{l}\text { Formulation, } \\
\text { Dose and Route } \\
\text { of } \\
\text { Administration }\end{array}$ & $\begin{array}{l}\text { - Formulation : allogeneic mesenchymal stem cells derived from bone } \\
\text { marrow } \\
\text { - Dose : } 1.0 \times 10^{6} \text { cells } / \mathrm{kg} \text {, every two weeks, a total of } 3 \text { infusions } \\
\text { - Route : intravenous infusion } \\
\text { - Infusion rate: } 2-4.5 \mathrm{ml} / \mathrm{min} \\
\text { Patients weighing less than } 50 \mathrm{~kg}, \mathrm{SCM}-\mathrm{CGH} \text { should be infused } \\
\text { slowly over } 10 \text { minutes }\end{array}$ \\
\hline Study Duration & $\begin{array}{l}\text { Total follow-up period for each patient is } 12 \text { weeks from the last } \\
\text { administration of drug. }\end{array}$ \\
\hline Population & Estimated enrollment : 1 \\
\hline
\end{tabular}




\begin{tabular}{|c|c|}
\hline $\begin{array}{l}\text { Inclusion } \\
\text { Criteria }\end{array}$ & $\begin{array}{l}\text { - Male and female patients of ages } \geq 20 \text { years and } \leq 60 \text { years } \\
\text { - AD patients diagnosed by the criteria of Hannifin and Rajka } \\
\text { - Subacute or chronic AD patients that have been present for at least } \\
6 \text { months } \\
\text { - Moderate-to-severe AD patients with SCORAD score }>20 \\
\text { - Patients willing to sign the informed consent form }\end{array}$ \\
\hline & $\begin{array}{l}\text { - Symptoms of systemic infection at baseline visit } \\
\text { - Asthma at baseline visit } \\
\text { - Treatment with systemic steroids, systemic immunosuppressants, } \\
\text { or systemic photochemotherapy within } 4 \text { weeks before baseline } \\
\text { visit } \\
\text { - Treatment with topical steroids, oral antibiotics, or topical } \\
\text { antibiotics within } 2 \text { weeks before baseline visit } \\
\text { - Treatment with drugs contraindicated for combination } \\
\text { - Pregnant or breast-feeding women or sexually active women of } \\
\text { childbearing potential who are unwilling to practice contraception } \\
\text { during the study } \\
\text { - Treatment with another investigational drug within } 30 \text { days before } \\
\text { baseline visit } \\
\text { - Creatinine }>2 x \text { upper limit of normal (ULN) at screening visit } \\
\text { - AST/ALT > 2x upper limit of normal (ULN) at screening visit } \\
\text { - Subjects who had a hypersensitivity to antibiotics or antimycotics } \\
\text { - Subjects who had a serious adverse events during stem cell } \\
\text { therapy } \\
\text { - Any medical or psychiatric condition which, in the opinion of the } \\
\text { investigator, would place the patient at risk, interfere with } \\
\text { participation in the study, or interfere with the interpretation of } \\
\text { study results }\end{array}$ \\
\hline $\begin{array}{l}\text { Concomita } \\
\text { treatment }\end{array}$ & $\begin{array}{l}\text { Treatment with the following concomitant medication is permitted } \\
\text { during study paticipation } \\
\text { (1) Concomitant medications that the patients have used before the } \\
\text { participation in present study are permitted, unless those }\end{array}$ \\
\hline
\end{tabular}




\begin{tabular}{|c|c|}
\hline & $\begin{array}{l}\text { medications do not affect the analysis of efficacy or the safety } \\
\text { of study drug. } \\
\text { (2) Symptomatic treatments: emollients not containing } \\
\text { corticosteroid, low potent (Group 6 7) topical corticosteroids, } \\
\text { antihistamines, or anti-inflammatory drugs } \\
\text { (3) Temporarily treated medications for the treatment of other } \\
\text { diseases or adverse reactions are permitted after the discussion } \\
\text { with the clinician. } \\
\text { (4) All detailed information regarding concomitant treatments } \\
\text { (including the treatment for diseases other than AD) will be } \\
\text { recorded in CRF. }\end{array}$ \\
\hline $\begin{array}{l}\text { Prohibited } \\
\text { Concomitant } \\
\text { Treatment }\end{array}$ & $\begin{array}{l}\text { Treatment with the following medications are prohibited during } \\
\text { study participation. } \\
\text { (1) Immunomodulators } \\
\text { (2) High potency (Group 1 5) topical corticosteroids } \\
\text { (3) Systemic corticosteroids } \\
\text { (4) Systemic photochemotherapy } \\
\text { (5) Live vaccination } \\
\text { (6) Other treatment considered to affect the immune function } \\
\text { When the usage of prohibited concomitant treatments are required } \\
\text { to treat patients during the study period upon clinician's decision, } \\
\text { those patients will be withdrawn from the clinical study and will be } \\
\text { recorded in the last page of case report form (CRF). }\end{array}$ \\
\hline
\end{tabular}




\begin{tabular}{|c|c|c|c|c|c|c|}
\hline \multirow{9}{*}{$\begin{array}{l}\text { Detailed Study } \\
\text { Design }\end{array}$} & Visit No. & Visit 1 & Visit 2 & Visit 3 & Visit 4 & Visit 5 \\
\hline & $\begin{array}{l}\text { Week } \\
(+ \text { Day) }\end{array}$ & $\begin{array}{l}\text { Within } 4 \\
\text { Weeks }\end{array}$ & 0 & $2( \pm 3)$ & $4( \pm 3)$ & $6( \pm 3)$ \\
\hline & $\begin{array}{l}\text { Nomen- } \\
\text { clature }\end{array}$ & $\begin{array}{l}\text { Screening } \\
\text { visit }\end{array}$ & Baseline visit & \multicolumn{2}{|c|}{ Treatment visit } & $\begin{array}{l}\text { Midterm } \\
\text { visit }\end{array}$ \\
\hline & Assessment & $\begin{array}{l}\text { Screening } \\
\text { Evaluation }\end{array}$ & Administration & Administration & Administration & Evaluation \\
\hline & & & & & & \\
\hline & Visit No. & Visit 6 & Visit 7 & Visit 8 & Visit 9 & Visit 10 \\
\hline & $\begin{array}{c}\text { Week } \\
\text { (+ Day) }\end{array}$ & $8( \pm 3)$ & $10( \pm 3)$ & $12( \pm 3)$ & $14( \pm 3)$ & $16( \pm 3)$ \\
\hline & $\begin{array}{l}\text { Nomen- } \\
\text { clature }\end{array}$ & \multicolumn{4}{|c|}{ Mieterm visit } & Final visit \\
\hline & Assessment & \multicolumn{5}{|c|}{ Evaluation of efficacy and safety } \\
\hline $\begin{array}{l}\text { Evaluation } \\
\text { Criteria }\end{array}$ & \multicolumn{6}{|c|}{$\begin{array}{l}\text { - Primary efficacy endpoints } \\
\text { Mean relative reduction in the severity of AD at } 12 \text { weeks } \\
\text { after administration of three doses evaluated by EASI, } \\
\text { IGA, and SCORAD score } \\
\text { - Secondary efficacy endpoints } \\
\text { Serum level of biomarkers (IgE, Eonsiophil count, ECP) }\end{array}$} \\
\hline $\begin{array}{l}\text { Tolerability and } \\
\text { Safety } \\
\text { Assessment }\end{array}$ & \multicolumn{6}{|c|}{$\begin{array}{l}\text { Adverse reactions, Clinical pathological analysis (hematology, blood } \\
\text { chemistry and urine examination), Physical examination, Vital sign }\end{array}$} \\
\hline
\end{tabular}


口 Study Schedule and Analysis Variables

\begin{tabular}{|c|c|c|c|c|c|c|c|c|c|c|}
\hline Period & $\begin{array}{l}\text { Scree } \\
\text { ning }\end{array}$ & \multicolumn{3}{|c|}{ Treatment } & \multicolumn{5}{|c|}{ Follow-up } & \multirow{2}{*}{$\begin{array}{c}\text { Closing } \\
10\end{array}$} \\
\hline Visit & 1 & 2 & 3 & 4 & 5 & 6 & 7 & 8 & 9 & \\
\hline Week & $\begin{array}{c}\text { Within } \\
-4 w\end{array}$ & $\mathbf{0 w}$ & $2 \mathrm{w} \pm 3 \mathrm{~d}$ & $4 w \pm 3 d$ & $6 w \pm 3 d$ & $8 w \pm 3 d$ & $10 w \pm 3 d$ & $12 w \pm 3 d$ & $14 \mathrm{w} \pm 3 \mathrm{~d}$ & $16 w \pm 3 d$ \\
\hline Written consent & O & & & & & & & & & \\
\hline Pre-treatment medications & $\bigcirc$ & & & & & & & & & \\
\hline Demographic investigation & O & & & & & & & & & \\
\hline Medical history & O & & & & & & & & & \\
\hline Physical examination & O & & & & & & & & & O \\
\hline Vital sign & O & O & O & O & O & O & O & O & O & O \\
\hline Penicillin skin test & O & & & & & & & & & \\
\hline Pregnancy test ${ }^{1)}$ & O & & & & & & & & & O \\
\hline Clinical laboratory test $\left.{ }^{2}\right)$ & $\mathrm{O}$ & $\mathrm{O}$ & O & O & O & O & & 0 & & 0 \\
\hline Chest X-ray & O & & & & & & & & & O \\
\hline ECG & O & & & & & & & & & O \\
\hline Inclusion/Exclusion & O & O & O & O & & & & & & \\
\hline SCORAD, IGA, EASI, BSA & O & O & O & O & O & O & O & O & O & O \\
\hline Total IgE, ECP & O & & O & O & O & & & & & O \\
\hline Biomarker & O & & O & O & O & O & & O & & O \\
\hline Administration of Drug & & O & O & O & & & & & & \\
\hline Adverse reactions & & $\mathrm{O}^{3)}$ & 0 & O & 0 & O & O & O & O & O. \\
\hline Combination drugs & & O & O & O & O & O & O & O & O & O \\
\hline
\end{tabular}

1) Urine HCG examination is performed on women of childbearing potential and the result should be checked before drug administration.

2)

Hematology Hemoglobin, Hematocrit, RBC, WBC, WBC different cell count, Platelet

Blood Chemistry Alkaline phosphatase, BUN, Creatinine, SGPT(ALT), SGOT(AST), Albumin, Total protein,

Total bilirubin, Uric acid, Glucose, Cholesterol, Na, K, Cl, Calcium, Phosphorus

Urinalysis: $\quad$ Specific Gravity, Color, $\mathrm{pH}$, Protein, Glucose, Bilirubin, Blood, WBC

3) Biomarker For molecular genetic testing, SST (tube $5 \mathrm{~mL} * 3$ ea, total $15 \mathrm{~mL}$ ) blood is collected at the scheduled visit and delivered to SM Life Science Co., Ltd., the sponsor of the clinical trial. At the 2nd and 3rd IP medication visits (Visit 3, Visit 4), blood is collected before IP medication. As a molecular genetic test, IgG1, IL-4, IL-17, IFN-gamma, IL-6, IL-5, TGF-b1, ICOSL, ACh, IL-13, IL-22, and TARC/CCL-17 are tested.

4) Adverse reactions are assessed for 4 hours after drug administration 
A
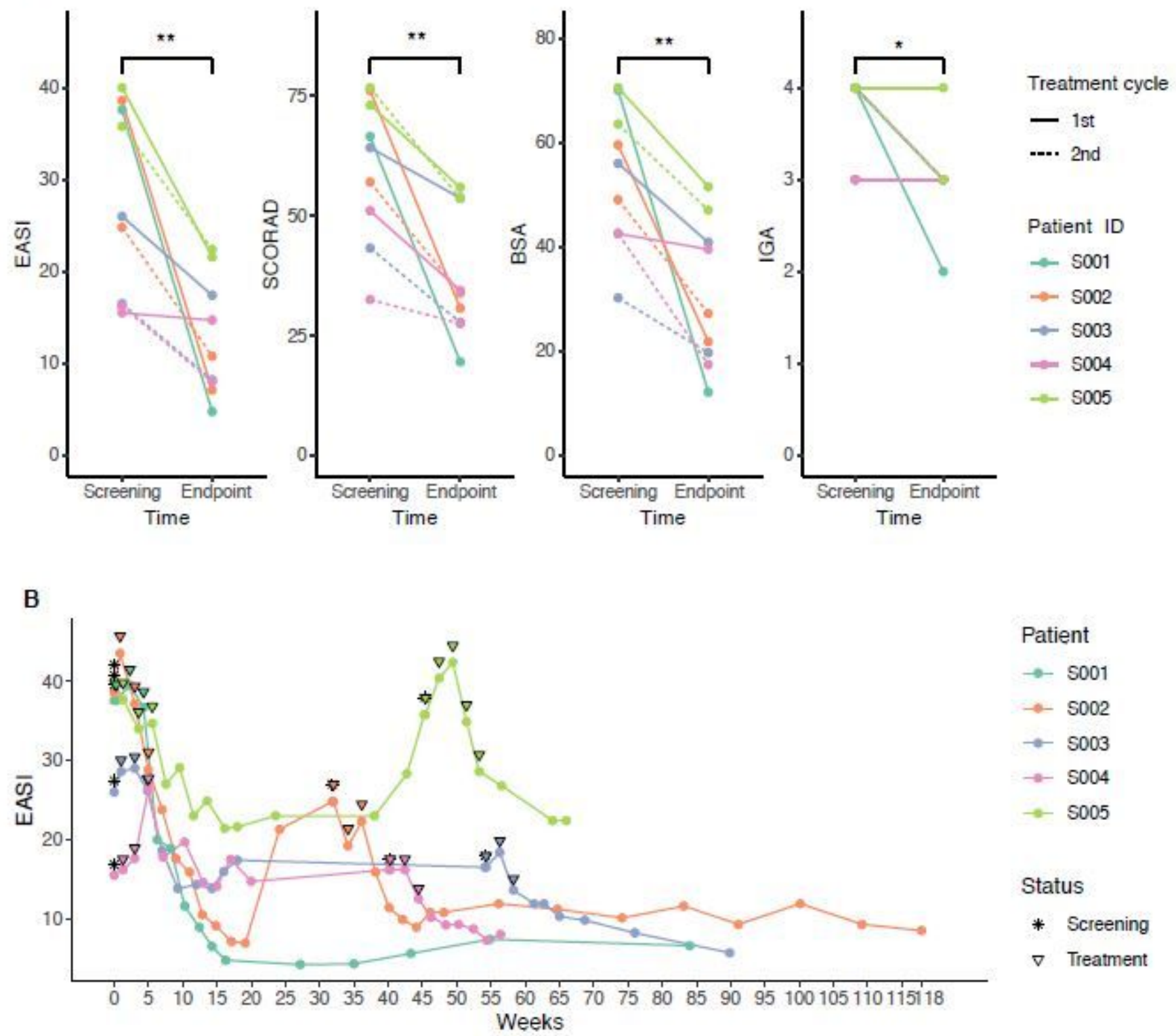

Patient

$\rightarrow$ S001

- 5002

$\rightarrow-\mathrm{S} 003$

$\rightarrow-5004$

$-\$ 005$

Status

* Screening

$\nabla$ Treatment

\section{Figure 1}

Clinical response of patients with atopic dermatitis to clonal mesenchymal stem cell therapy. (A) Comparison of clinical response between screening and endpoint (followed up at about 16 weeks). The significance of the results was evaluated with Wilcoxon signed-rank test. EASI: Eczema Area and Severity Index, SCORAD: SCORing Atopic Dermatitis, BSA: Body Surface Area, IGA: Investigator Global Assessment. (B) Changes in Eczema Area and Severity Index (EASI) score of atopic dermatitis patients treated with clonal mesenchymal stem cells. ${ }^{*} p<0.01,{ }^{*} p<0.05$ 
A

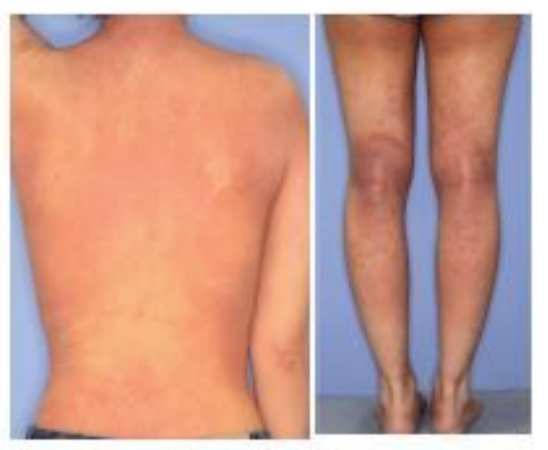

Cycle\#1 visit 2

Treatment \#1

B

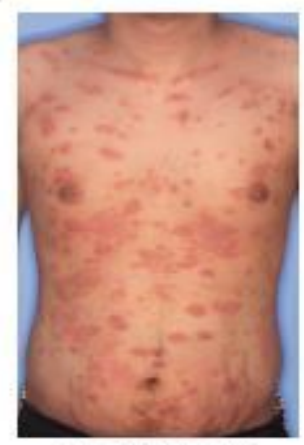

Cycle\#1 visit 1

Screening

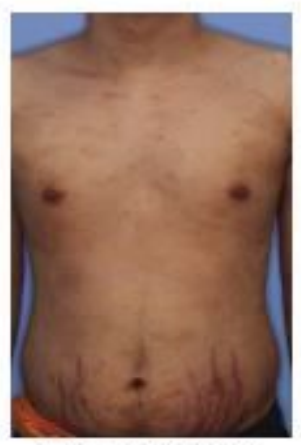

Cycle\#1 visit 10 f/u 17 weeks

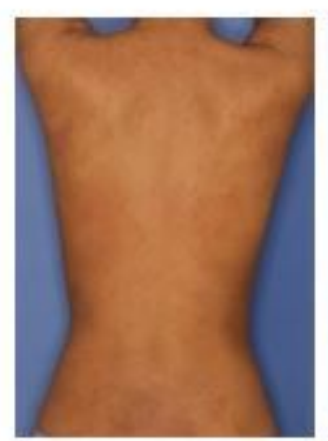

Cycle\#1 visit 10 f/u 16 weeks



Cycle\#2 visit 2 Treatment \#1


Cycle\#1 visit 12 f/u 35 weeks

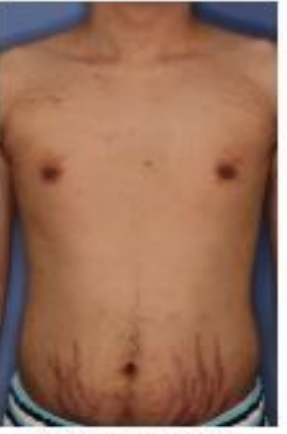

Cycle\#2 visit 8 f/u 12 weeks

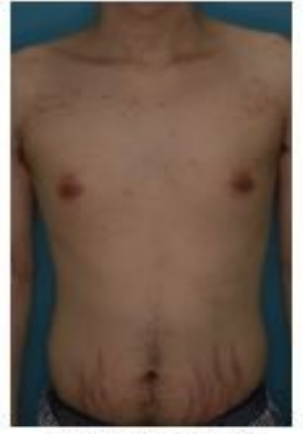

Cycle\#2 visit 18 f/u 86 weeks

\section{Figure 2}

Photographs of atopic dermatitis patients with good long-term response to clonal mesenchymal stem cell therapy. (A) S001 patient. (B) S002 patient. f/u: follow-up. 